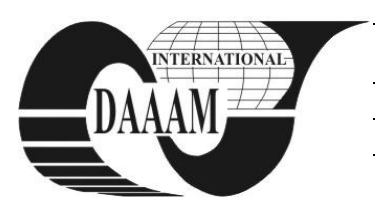

Annals of DAAAM for 2012 \& Proceedings of the 23rd International DAAAM Symposium, Volume 23, No.1, ISSN 2304-1382 ISBN 978-3-901509-91-9, CDROM version, Ed. B. Katalinic, Published by DAAAM International, Vienna, Austria, EU, 2012 Make Harmony between Technology and Nature, and Your Mind will Fly Free as a Bird Annals \& Proceedings of DAAAM International 2012

\title{
RISK MANAGEMENT IN PRODUCT DEVELOPMENT PROCESS
}

\author{
SUSTEROVA, M[onika]; LAVIN, J[aak] \& RIIVES, J[ueri]
}

\begin{abstract}
The aim of this article is to stress the importance of necessary changes against risks with the help of a case study in real company called Meiren Engineering. The introduction focuses on the explanation of the following term: product development process and project risk management. Next part is focused on the proposal and monitoring risks. The conclusion is focused on particular solutions to eliminate these risks and follow illustrate these risks in the matrix grid.

Keywords: risk management, potential risk, elimination of risk, risk assessment
\end{abstract}

\section{INTRODUCTION}

The competitiveness in global and local markets highlights the importance of design, quality, productivity, multi-company collaboration, optimal price levels and production process predictability. The manufacturers are under pressure to keep and increase their places in the market. To improve their ability to innovate, bring products to the market faster, and reduce manufacturing bottlenecks, the manufacturers have been improving their product development and management abilities. Companies have to invest more money to product lifecycle management and enterprise resource planning systems [1, 2]. Risk management should be an integral part of the management of each project. Quality risk management, its implementation and integration of management systems represents a significant added value.

\section{PROJECT MANAGEMENT IN COMPANY}

When an industrial company launches a new product at the market the goal is to obtain a viable business. Engineering design is a purposeful activity directed toward the goal of fulfilling human needs, particularly

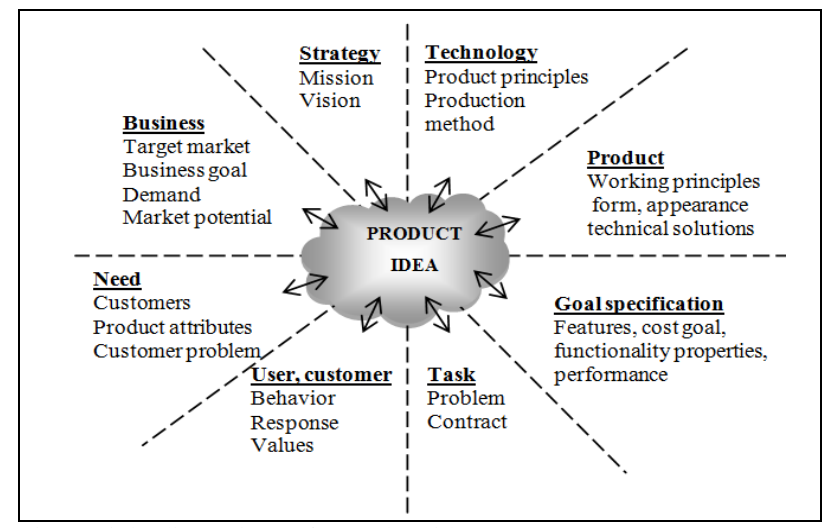

Fig.1. Eight dimensions of a product idea [6] those which can be met by the technological factors of our culture. New product idea is as the trigger for a product development project [5]. According model at the fig. 1 members of team selected company may in an initial paradoxical situation find relevant discourses of a product idea [5].

\subsection{Product development process}

Product development projects should include also risk assessment, that allows managers to identify and measure the risks associated with resource constraints and then develop appropriate responses. It is a cycle by means of which an innovative firm routinely converts ideas into commercially viable goods or services. Companies typically see new product development as the first stage in generating and commercializing new products within the overall strategic process of product life cycle management used to maintain or grow their market share [9].

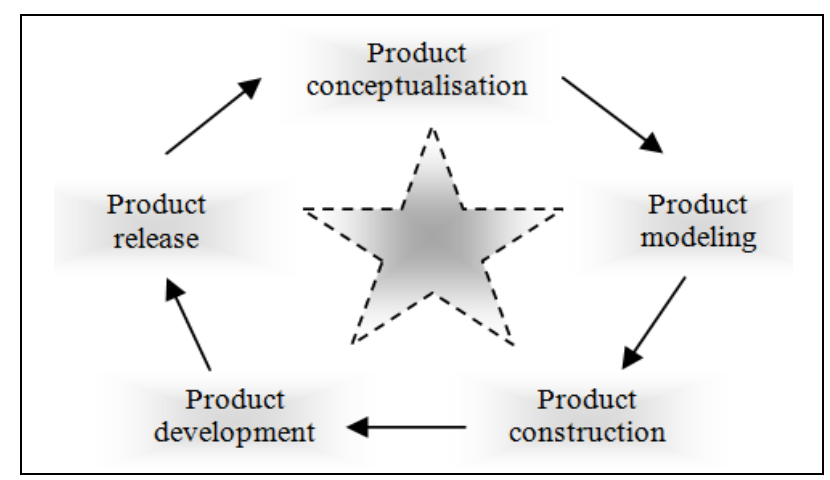

Fig. 2. Product development process [7]

In business and engineering, new product development is the term used to describe the complete process of bringing a new product to market. A product is a set of benefits offered for exchange and can be tangible (that is, something physical you can touch) or intangible (like a service, experience, or belief). There are two parallel paths involved in the new product development process: one involves the idea generation, product design and detail engineering; the other involves market research and marketing analysis.

\section{PROJECT RISK MANAGEMENT}

Project risk is an uncertain event, feature, activity or situation that can have a positive or negative effect on the outcome of a project. Project risk and opportunity management formally identifies, assesses and plans for uncertainty [7]. 
PMBOK defines the project constraint as" an applicable restriction or limitation, either internal or external to the project that will affect the performance of the project or process [11]."

Risk management protects a project by maximizing opportunities and value whilst minimizing the threat. It is a prerequisite of all effective project management solutions [3].

\subsection{Identifying Risk}

Risk management requires you to identify potential risks; risk being anything that can possibly harm or have a negative impact on the project. Risk managers generally approach the search for potential risk from two distinct angles: source analysis and problem analysis. Source analysis seeks to look at the potential sources of risk whereas problem analysis looks at specific individual problems that could arise [9].

\subsection{Risk Assessment}

Once risks have been identified, the next logical step in risk management is assessment. Risk assessment, as mentioned earlier, measures the probability of an identified risk actually taking place, as well as the amount of loss that would be suffered were the risk to actually occur. Loss and probability are usually placed in a prioritized list, with those risks that are most probable and that stand to generate the most loss given the most attention. In reality, a lot of guess work goes into this phase of risk management as at times it is almost impossible to evaluate and know the true likelihood as to whether a potential risk will occur or not $[3,12]$.

\subsection{Indication of potential risks to the matrix grid}

The Risk Impact/Probability Chart provides a useful framework that helps decide which risks need attention [11]. The Risk Impact/Probability Chart is based on the principle that a risk has two primary dimensions:

1.Probability - A risk is an event that "may" occur. The probability of it occurring can range anywhere from just above 0 percent to just below 100 percent. (Note: It can't be exactly 100 percent, because then it would be a certainty, not a risk. And it can't be exactly 0 percent, or it wouldn't be a risk.)

2. Impact - A risk, by its very nature, always has a negative impact. However, the size of the impact varies in terms of cost and impact on health, human life, or some other critical factor [10].

The chart allows you to rate potential risks on these two dimensions. The probability that a risk will occur is represented on one axis of the chart - and the impact of the risk, if it occurs, on the other. You use these two measures to plot the risk on the chart. This gives you a quick, clear view of the priority that you need to give to each. You can then decide what resources you will allocate to managing that particular risk.

The basic form of the Risk Impact/Probability Chart is shown in figure 3 , below [10].

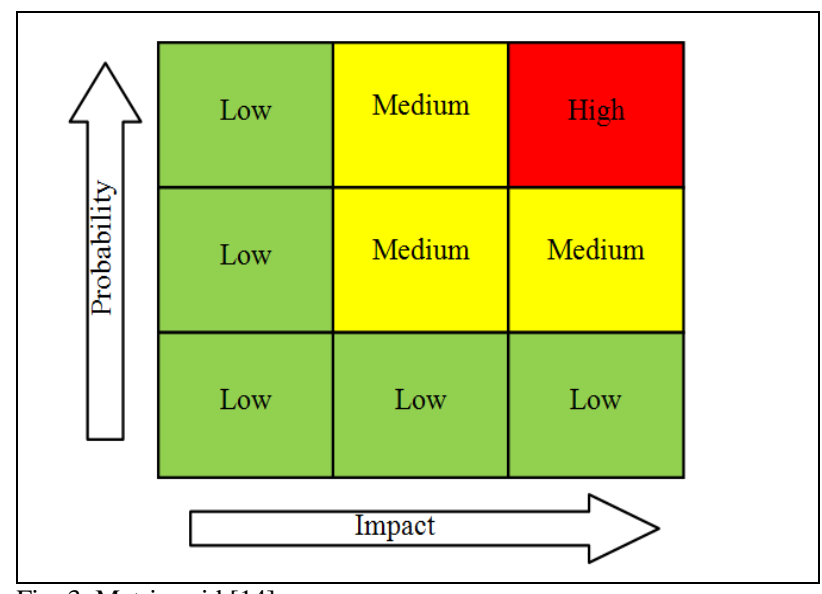

Fig. 3. Matrix grid [14]

\section{CASE STUDY}

Goal Meiren Engineering is to offer a complete service from generating ideas of machines and devices up to drafting final assembly drawings.

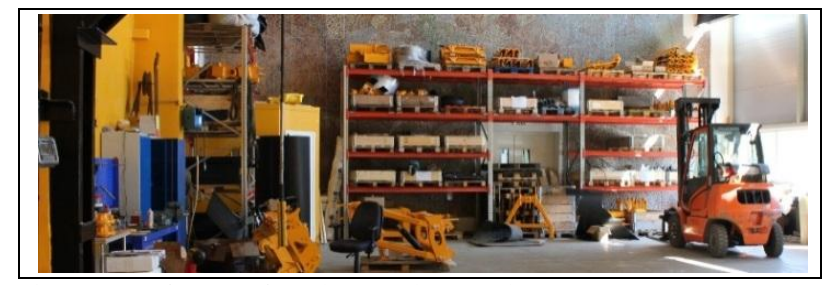

Fig. 4. Manufacture of products and snow plows [13]

Meiren Engineering can also improve the existing drawings presented by clients or draft a part of a client's project via subcontracting [13].

The importance of risk management cannot be overstated. This is a fundamental part of doing business that must be addressed appropriately for the company to be successful. Risks are just part of doing business and by having a procedure in place to deal with them does make a difference on their impact. Some causes of risks may occur during all phases of product life cycle, some are specific for individual phase [9]. We can see selected eight risks factors that may occur in the selected company. These risks are selected by product development project in Merien Engineering.

Selected potential risks by product development project and the proposed measures:

1. Incompetent management (lack the necessary qualifications and skills, poor organization)

- diversification of company management

- the involvement of external consultant

2. External risk factors (factors outside the direct control of the organization)

- development of catastrophic scenarios, recovery plans

- creating team for crisis management

- data storage in a safe place

3. Information technology (disruption can be caused by internal factors (employees) or external factors (viruses)) 
- authorized of documentation and requires access to system and data

- limiting access to system and to data

4. Lack of marketing ( inaccurate, delayed or unavailable information concerning prices, products, advertising, sales support)

- the introduction of marketing research

- evaluation of pricing strategies compared to competitive products and prices

- evaluate the effectiveness of advertising and sales promotion

5. The organization is lagging behind in technological development (management does not have access to information associated with the current technological development)

- monitoring of competitors

- technical literature

- visits to seminars, conferences, business meetings, exhibitions

- regular summary information on technological development
6. High staff turnover (problems in the organization, for example: wages under industry-average, lack of investment in development of the employees, wrong systems for monitoring)

- encouraging vertical communication

- keeping active company culture

7. Failure safety (lack of knowledge regarding the laws for the protection and safety at work)

- obtain competent legal advice for business relating to the company for the protection and safety

- periodic verification of the legal advice they are applied to the procedures and security measures

8. Organization lacks quality strategy (incomplete or inaccurate information regarding the changes about competition, products and customer preferences)

- development of strategic plans for top management, which will include a vision of the organization

- periodic review directions and priorities set top management to ensure they are still valid.

\begin{tabular}{|c|c|c|c|}
\hline & Potential risk & Elimination of potential risk & $\begin{array}{l}\text { Risks in } \\
\text { matrix } \\
\text { grid }\end{array}$ \\
\hline 1 & $\begin{array}{l}\text { Technical capability of the product does not meet } \\
\text { the expectations and wishes to the customers, the } \\
\text { product does not have assumption that will succeed } \\
\text { in the market }\end{array}$ & $\begin{array}{l}\text { The risks of the project are clearly defined in advance, before beginning } \\
\text { Through market research }\end{array}$ & $\begin{array}{l}\text { Medium } \\
\text { risk }\end{array}$ \\
\hline 2 & $\begin{array}{l}\text { Complicated design of product for manufacturing, } \\
\text { the expenses of the product development process } \\
\text { exceeded the limits and budget forecast }\end{array}$ & $\begin{array}{l}\text { Project managers must achieve balance among these resource constraints: } \\
\text { time, funds, and required quality }\end{array}$ & High risk \\
\hline 3 & $\begin{array}{l}\text { The durability of the product development process } \\
\text { is longer as it was planned and therefore the } \\
\text { product could not enter to the market in a right time }\end{array}$ & Anticipating changes in technology and estimating the product life cycle & Low risk \\
\hline 4 & $\begin{array}{l}\text { The problems in manufacturing are caused very } \\
\text { complicated and complexity of the product, } \\
\text { increase the cost of producing the product }\end{array}$ & Set a limit on the amount of risk, that will be accepted & Low risk \\
\hline 5 & Critical people left the project & $\begin{array}{l}\text { Improved communications through project } \\
\text { Increased motivation through: financial rewards, gift vouchers, vouchers for } \\
\text { birthday, staff training, career advancement, services paid by company: } \\
\text { foreign visits, courses, training } \\
\text { Change the project manager in project management }\end{array}$ & High risk \\
\hline 6 & $\begin{array}{l}\text { Critical resources needed for the project was not } \\
\text { available at the right times }\end{array}$ & $\begin{array}{l}\text { Developing plans and practices, that notify the most serious risks } \\
\text { Planning and monitoring of risks by introducing standardized connection } \\
\text { between risk management processes, enabling quick respond to changes in } \\
\text { other people involved in the development and take into account changes the } \\
\text { objectives of the project }\end{array}$ & $\begin{array}{l}\text { Medium } \\
\text { risk }\end{array}$ \\
\hline 7 & The project missed critical milestones & $\begin{array}{l}\text { Compliance methods at each stage in process of product development } \\
\text { Improve the process more accurate by redistributing of means } \\
\text { Development alternative methods - each partial goal can be achieved by } \\
\text { several methods }\end{array}$ & $\begin{array}{l}\text { Medium } \\
\text { risk }\end{array}$ \\
\hline 8 & $\begin{array}{l}\text { Cost of the product exceeded the market } \\
\text { expectations, exceeded budget }\end{array}$ & $\begin{array}{l}\text { Anticipating and responding to expected competitor reaction. } \\
\text { Periodic and detailed estimates throughout the project } \\
\text { Inclusion of a project manager who has experience with audits and } \\
\text { inspections that are done before assigning tasks }\end{array}$ & Low risk \\
\hline 9 & $\begin{array}{l}\text { Introduction of new tools, technology, or processes } \\
\text { during the project }\end{array}$ & $\begin{array}{l}\text { Testing of new tools, technology or processes for a specified period } \\
\text { Analysis of internal and external environment (market, customers, } \\
\text { competitors, strengths and weaknesses of the company) }\end{array}$ & $\begin{array}{l}\text { Medium } \\
\text { risk }\end{array}$ \\
\hline 10 & $\begin{array}{l}\text { The competence of the product development team } \\
\text { is not at this level as it was expected and there is a } \\
\text { lack of key competence }\end{array}$ & Involvement of an experienced project manager to team & $\begin{array}{l}\text { Medium } \\
\text { risk }\end{array}$ \\
\hline 11 & $\begin{array}{l}\text { The project management team don't follow the best } \\
\text { practices and rules in project management }\end{array}$ & Review the decision to accept best alternative & Low risk \\
\hline 12 & $\begin{array}{l}\text { The subcontractors and supplies do not fulfill the } \\
\text { schedule }\end{array}$ & $\begin{array}{l}\text { Effective communication, regular exchange of information between } \\
\text { subcontractors and supply }\end{array}$ & Low risk \\
\hline 13 & $\begin{array}{l}\text { The mistakes in design cause problems in } \\
\text { manufacturing. There are misunderstandings } \\
\text { between designers and manufacture. Redesign is } \\
\text { expensive and takes additional time }\end{array}$ & $\begin{array}{l}\text { Optimizing the cost of risk management and reducing losses due to } \\
\text { incorrect decisions }\end{array}$ & High risk \\
\hline
\end{tabular}

Tab. 1. Elimination of potential risk 
- sharing information on competitors, products, customers or regular and legal changes to all related activities

- the introduction of vertical and horizontal communication, which allows the rapid identification and resolution, which prevents the achievement of strategic objective.

The proposed measures are very good prevention as to avoid future potential risks. These measures can provides enhanced planning and better decision making, rather than crisis management.

\subsection{Found potential risk in process of product development project management in Meiren Engineering}

Risk management falls into the arena of project planning. In the individual steps in the algorithm product development process in Meiren Engineering can occur risk see table 1 . The goal is to find different ways of elimination, if risk occurs.

\subsection{Indication of the potential risks identified in the matrix grid}

Result of the risk matrix simply and easily determine which potential risks concentrate Meiren Engineering.

\begin{tabular}{|c|c|c|c|}
\hline Risk \# & $\begin{array}{c}\text { Probability of } \\
\text { Occurrence }\end{array}$ & Risk \# & Impact of risk \\
\hline 1. & $\mathbf{1 2}$ & 1. & $\mathbf{5 , 5}$ \\
\hline 2. & $\mathbf{1 4 , 5}$ & 2. & $\mathbf{1 4 , 5}$ \\
\hline 3. & $\mathbf{5 , 5}$ & 3. & $\mathbf{4}$ \\
\hline 4. & $\mathbf{2}$ & 4. & $\mathbf{9}$ \\
\hline 5. & $\mathbf{1 0 , 5}$ & 5. & $\mathbf{1 4 , 8}$ \\
\hline 6. & $\mathbf{9 , 8}$ & 6. & $\mathbf{7}$ \\
\hline 7. & $\mathbf{5}$ & 7. & $\mathbf{9}, \mathbf{5}$ \\
\hline 8. & $\mathbf{1}$ & 8. & $\mathbf{1 2 , 5}$ \\
\hline 9. & $\mathbf{7}$ & 9. & $\mathbf{6}$ \\
\hline 10. & $\mathbf{6}$ & 10. & $\mathbf{4 , 8}$ \\
\hline 11. & $\mathbf{3 , 5}$ & 11. & $\mathbf{1 0}$ \\
\hline 12. & $\mathbf{3 , 5}$ & 12. & 13. \\
\hline 13. & $\mathbf{1 2}$ & 1 & $\mathbf{2}$ \\
\hline
\end{tabular}

Tab. 2. Identification and risk assessment

In the figure 5 we can see identified and assessed risks based of probability and impact in product development project management. These risks are situated in matrix grid after consultation with the manager Meiren Engineering.

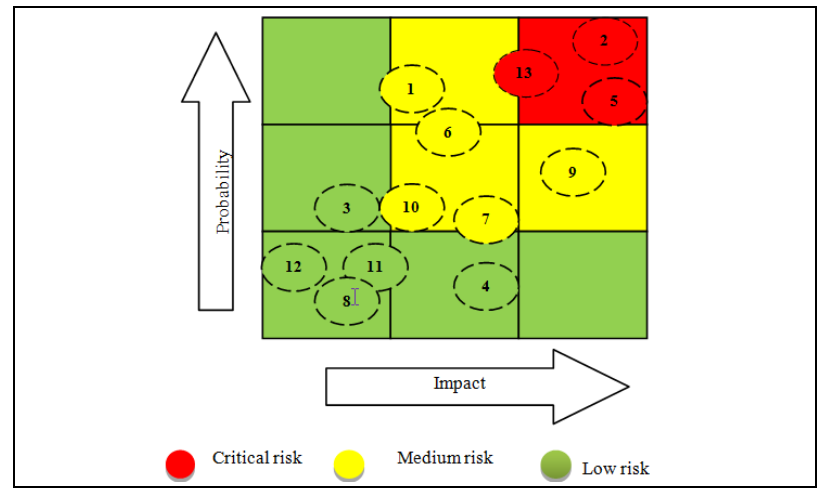

Fig. 5. Risks in the matrix grid

The most critical risks are in the red line, when the risk level is too high to start with the project.

\section{CONCLUSION}

In nowadays manufacturing the processes turn more complicated and faster. The pallet of possible solution is wide and decisions more sophisticated. Therefore here is extremely importance of new topics about identifying risks, managing risks and avoidance of risks. We have worked the topic based as the activities and experiences of a real company which is familiar with a product development process of quite sophisticated products.

\section{ACKNOWLEDGEMENTS}

This research was supported by Innovative Manufacturing Engineering Systems Competence Centre IMECC, co-financed by European Union Regional Development Fund (project EU30006).

\section{REFERENCES}

[1] Riives, J.; Karjust, K.; Küttner, R.; Lemmik, R.; Koov, K.; Lavin, J. (2012). Software development platform for integrated manufacturing engineering system. In: Proceedings of the 8th International Conference od DAAAM Baltic Industrial Engineering 19-21st April 2012. . Tallinn, Estonia:, 2012, 555 560. ISBN:978-9949-23-265-9

[2] Karjust, K.; Küttner, R.; Pääsuke, K. (2010). Adaptive web based quotation generic module for SME's. Küttner, R. (Toim.). Proceedings of the 7th international conference of DAAAM Baltic industrial engineering, 22-24th april 2010, Tallinn, Estonia, 375-380

[3] Heldman, K. Project Manager's Spotlight on Risk Management, SYBEX Inc., 2005. 239 s. ISBN: 0-7821-4411-X

[4] New product development. (2012). Available from: http://en.wikipedia.org/wiki/New_product_development Accessed on: 2012-09-04

[5] Karnie, Arie; Reich, Yoram (2011). Managing the Dynamic of New Product Development Processes. A new Product Lifecycle Management Paradigm. Springer. p. 13. ISBN 978-0-85729-569-9

[6] Product Development (2010). Available from: http://www.ravetech.com/services_devlopment.php Accessed on: 2012-06-01

[7] Project Risk Management: What is project risk management. Available from: http://www.projen.co.uk/downloads/Risk \%20Assessment \%20BIP.pdf: Accessed on: 2012-05-29

[8] Understanding Risk Analysis and Risk Management. Available from: http://www.enterprise-pm.com/pmbasics/risk-analysis: Accessed on: 2012-06-03

[9] Dolezal, J., Machal B., Lacko, B.: Project management by IPMA, Grada Publishing, 2009. 512s. ISBN 978-80-247-2848-3

[10] Risk Impact/Probability Chart. Learning to Prioritize Risks. Available from: http://www.mindtools.com/pages/article/ newPPM_78.htm: Accessed on: 2012-05-28

[11] A guide to the project management body of knowledge: PMBOK ${ }^{\circledR}$ guide. 2004. Project Management Institute, Inc. Newton Square, PA, USA. $3^{\text {rd }}$ edition. 390 p. ISBN 10:1-930699-45-X

[12] Lõun, K; Riives, J; Otto, T. (2011). Evaluation of the operation expedience of technologica resources in a manufacturing network. Estonian Journal of Engineering, (17), 1, 51-65.

[13] Available from: http://www.meiren.ee/ Accessed on: 2012-06-02

[14] Cox's risk matrix theorem and its implications for project risk management. Available from: http://eight2late.wordpress.com/ 2009/07/01/cox's-risk-matrix-theorem-and-its-implications-forproject-risk-management/: Accessed on: 2012-06-08 